\title{
Primary Esophageal Tuberculosis
}

\author{
Apoorv Singh $^{1} \cdot$ Deepak Mittal $^{1} \cdot$ Vishesh Jain $^{1}$ (1) $\cdot$ Sushil Kumar Kabra ${ }^{2} \cdot$ Sandeep Agarwala ${ }^{1}$
}

Received: 8 May 2021 / Accepted: 22 June 2021 / Published online: 12 July 2021

(c) Dr. K C Chaudhuri Foundation 2021

To the Editor: Primary esophageal tuberculosis is a rare disease of the childhood. The most common symptom is dysphagia [1]. A 7-y-old boy presented with complaints of progressive dysphagia for the past 9 mo with no history of fever or respiratory symptoms. Contrast esophagogram and CECT showed narrowing of distal esophagus with proximal dilatation. There was no mediastinal lymphadenopathy, or lung lesions; however, celiac lymphadenopathy was present. UGI endoscopy revealed nodular growth in lower esophagus occupying almost whole of the lumen. Multiple endoscopic biopsies showed nonspecific inflammatory cells. FDG-PETCT scan demonstrated an increased uptake circumferentially in the lower esophagus and celiac lymph node. Histopathology of celiac lymph node showed epitheloid granulomas with Langhans giant cells. Antitubercular therapy was administered and patient became asymptomatic after 2 mo. The patient is doing well after $2 \mathrm{y}$ follow-up with normal imaging.

Gastrointestinal tuberculosis is a common disease in the developing world. The most common cause is ingestion of infected milk followed by infected sputum in patients suffering from pulmonary tuberculosis [2]. However, esophageal tuberculosis is rare and accounts for $0.07 \%-0.15 \%$ of gastrointestinal tuberculosis cases [3]. It mostly occurs in patients of pulmonary tuberculosis with mediastinal lymphadenopathy rather than primary involvement of esophagus. The main modalities of diagnosis of esophageal tuberculosis are CECT thorax and endoscopic biopsy. Endoscopic biopsy often does not include the tissues deeper to the submucosa. In the present case also, multiple endoscopic biopsies were inconclusive. Another point to emphasized is that uptake in PET is also present in inflammatory conditions. In our case, due to very high probability of tuberculosis on biopsy, a trial of ATT was planned. Although response to ATT has often been used as a retrospective confirmation of diagnosis in endemic areas, an attempt should be made to confirm the diagnosis before starting ATT.

\section{Declarations}

Conflict of Interest None.

\section{References}

1. Rana SS, Bhasin DK, Rao C, Srinivasan R, Singh K. Tuberculosis presenting as Dysphagia: clinical, endoscopic, radiological and endosonographic features. Endosc Ultrasound. 2013;2:92-5.

2. Rosario MT, Raso CL, Comer GM. Esophageal tuberculosis. Dig Dis Sci. 1989;34:1281-4.

3. Savage PE, Grundy A. Oesophageal tuberculosis: an unusual cause of dysphagia. Br J Radiol. 1984;57:1153-5.

Publisher's Note Springer Nature remains neutral with regard to jurisdictional claims in published maps and institutional affiliations.

Vishesh Jain

dr.vishesh79@gmail.com

1 Department of Pediatric Surgery, All India Institute of Medical Sciences, New Delhi 110029, India

2 Department of Pediatrics, All India Institute of Medical Sciences, New Delhi, India 